\title{
NURSE AIDE DECISION MAKING IN NURSING HOMES: FACTORS AFFECTING EMPOWERMENT
}

by

Tanni Chaudhuri, M.A., M.S. Texas Woman’s University

Dale Yeatts, PHD, University of North Texas

Texas Woman's University

Dept. of Sociology

CFO 305, PO Box 425887

Denton TX 76204

tchaudhuri@twu.edu

yeatts@unt.edu

\# 8178817889

Fax: 817-531-4202

Grant Support: 


\begin{abstract}
Aims and Objectives: This paper looks at factors affecting structural empowerment among nurse aides (NAs). Background: Structural empowerment can be defined as the actual rather than perceived ability to make autonomous decisions within an organization. Given the paucity of research on the subject, this study helps to close the gap by identifying factors that affect NA empowerment, that is, decision making among certified NAs. Method: The data for the study comes from self-administered surveys distributed among direct-care workers (DCWs) in 11 nursing homes (NHs) in a southern state in the United States. Four OLS Regression models were used to analyze the effect of demographic predictors, personal factors (competency, burnout and positive attitude) and structural characteristics (coworker and supervisor support, information availability and participation in decision making) on decision making. Results: Findings suggest race among demographic predictors, burnout among personal characteristics and supervisor support, and participation in decision-making among structural factors, significantly affect decision-making. Conclusion: It is important to explore race as one of the central determinants of structural empowerment among nurse aides, because the profession is characterized by high minority participation. In addition, the nature and type of burnout that propel decision making needs to be examined since other formal and informal credentials brought into the profession were not significant. Clinical Practice: The study explains the importance of shared governance and supervisor support working as distinct and allied practices that fosters nurse aide empowerment, which potentially could lead to better quality of care.
\end{abstract}

Keywords: Nurse Aide Empowerment, Decision Making, Structural Empowerment 


\section{INTRODUCTION}

Between the years 1950 and 1980, the elderly population in America doubled, and simultaneously the number of nursing homes and nursing home beds also greatly increased (Day \& Berman, 1989). Since this time, the focus of nursing homes has changed from a medical model to a person centered model, with a goal of a more "attractive, enjoyable and beneficial" place to live (Cready et al. 2008). Some of the initiatives have included the Eden Alternative, Green House Project and LEAP (Learn, Empower, Achieve, and Produce Training). All of these strategies have employed the idea of nursing aide (NA) empowerment with the rationalization that NA's are in the best position to make informed decisions because they have the first-hand knowledge of their residents (Yeatts \& Cready 2004).

Unfortunately there has been relatively little research focused on the factors that enhance NA empowerment. This paper helps to close the gap by identifying factors that affect NA empowerment, i.e. decision making among certified NAs. Provided below is a precise definition of empowerment (psychological versus structural) followed by a brief review of literature, examining NA empowerment.

\section{Empowerment: Psychological versus Structural}

Two dimensions of empowerment have been identified- psychological and structural/organizational. Psychological empowerment refers to an individual's feeling or perception of his/her contribution to the workplace and typically includes (i) meaningfulness of the work, (ii) perceived competency or self-efficacy, (iii) one's self determination and (iv) one's perceived impact on outcomes (Thomas \& Velthouse 1990; Sprietzer 1995). More specifically, the concept of 'meaningfulness' entails the value attached to the work in accordance with 
individual standards attached to it, while 'competency or self-efficacy' includes individual conviction in self capabilities (Sprietzer, 1995). 'Self-determination' refers to proactive efforts that go into initiating a procedure in the workplace and being able to persistently follow it through. Finally 'impact' refers to the individual perception that she/he is able to make changes and produce outcomes and is the reverse of perceived helplessness (Sprietzer 1995).

Psychological empowerment is thus largely affective-cognitive in nature and refers to one's 'perceived' sense of being able to make a difference in the work place.

Structural empowerment can be defined as the actual rather than perceived ability to make autonomous decisions within an organization. Mills and Ungson (2003) define structural empowerment as an employee's ability to make decision making and have the authority to plan and execute an appropriate course of action without having to consult with an immediate supervisors. In providing a generic definition, Siebert et al., (2004) refer to structural empowerment as "autonomous decision making capabilities". In the next segment, the likely predictors of structural empowerment/decision making in nursing homes will be examined briefly.

\section{REVIEW OF LITERATURE: DETERMINANTS OF DECISION MAKING AMONG} NA's

A review of the literature suggests that there are demographic as well as personal versus structural characteristics that impact decision making. These probable determinants of decision making among NAs include gender, burnout, positive attitude, competency, information availability, coworker and supervisor support, and participation in decision making. 


\section{Demographic determinants}

Gender in the workplace. It is not unreasonable to assume that gender affects a person's level of decision making. Nursing is often thought to be a feminine profession. Even within the domain of health care, there is an expectation with regards to the gender of the nurse practitioner. For instance, when a sample of both male and female nurse practitioners and physicians watched videotaped interactions between health care providers and their patients, the underlying assumption was that men were physicians and women were nurse practitioners (Horman, et al., 1987). A collaborative relationship between the nurse practitioner and the physician does not alter the initial gender stereotypes (Horman, et al., 1987). There is some evidence to the fact that men are preferred to be seen more as leaders over women, or the fact that both men and women prefer to work with men, rather than women (Kanter, 1979). It seems safe to assume that irrespective of the clustering of women in nursing, the traditional decision making roles would still be contingent on the gender of the NAs. This leads to our first hypothesis:

$H_{1}$ : Gender affects the extent of decision making.

Control variables: In addition to the main predictor variables specified above, demographic predictors including race, education, seniority in terms of age, marital status and number of children will also be taken into consideration while examining the overall determinants of decision making among NAs.

\section{Personal determinants}

Positive attitude of NAs. Positive attitude (also referred to as positive affect) has been reported to have an effect on decision making. Cohen and Pressman (2006) refer to positive affect as: "feelings that reflect a level of pleasurable engagement with the environment, such as 
happiness, joy, excitement, enthusiasm, and contentment" (Cohen and Pressman 2006). Positive attitude has been associated with stepping outside the boundary to help, less confusion about the work scenario and a greater knowledge of the situation (Isen, 2001). Since individual decisionmaking involves being able to act on one's own, positive attitude can potentially influence decision making.

Overall, positive affect refers to a sense of belonging to the workplace from which, an overall sense of gratification can be derived. For the purpose of analysis for this paper, the concept is limited to a sense of optimistic attitude that is derived from personal accomplishment in the workplace. NA's who exhibit positive attitudes can be expected to show more willingness to cater to the personal needs of nursing home residents, and thus more willing to make decisions about their well being

$\mathrm{H}_{2}$ : Positive attitude positively affects decision making.

Emotional exhaustion: A high level of burnout has its effects on helping professions including nursing (Cordes \& Dougherty 1993). Research has demonstrated that burnout takes its toll on staff turnover, absenteeism and decrease in the quality and quantity of care, negative attitude towards client and coworkers, as well as lack of commitment (Cordes \& Dougherty 1993). Given the extent of damaging consequences of burnout, it is likely to limit effective decision making among NAs.

Overall burnout is assessed to be an important deterrent in all kinds of work places (Toppinen-Tanner et al. 2002). The emotional aspect of burnout refers to the fatigue that results from being overworked (a situation, which can apply to nurses given the magnitude of the workload they deal with). Although exhaustion (emotional), cynicism (depersonalization) and professional efficacy (personal accomplishment) are assessed to be three different dimensions of 
burnout, research into the sequential processing of burnout (Maslach \& Jackson, 1981; Maslach, Jackson, \& Leiter, 1996), has validated exhaustion or emotional dimension of burnout as the likely precursor of depersonalization, which finally renders itself to lack of personal accomplishment (Toppinen-Tanner et al. 2002). Alternatively put burnout, which starts with emotional exhaustion, precedes a feeling of detachment, which precedes lack of attainment. One yardstick of workplace attainment could include decision making, since it is pivotal to nursing home practice. In effect, emotional exhaustion or burnout thus could impact decision making.

For the purpose of the current analysis the emotional aspect of burnout (exhaustion) will be singled out as antecedent to decision making. It seems reasonable to assume that in the presence of high levels of burnout, effective decision-making cannot be achieved.

$H_{3}$ : Burnout negatively affects decision making.

Competency. Kanter (1989) has argued that the development of decision making and front line roles, will be half realized without adequate training and education. For instance, in the early years of HIV/AIDS in America, community health nurses were deemed appropriate leaders who could disseminate important information on the subject, after receiving training in the area (Henke Jones 1988). This training pertained to leadership in clinics, industry, schools and homes and their competency was thus assessed to be cardinal in creating AIDS awareness on college campuses (Henke Jones, 1988).

It is safe to assume that leadership includes timely and autonomous decision making among nurses when they are the frontline workers. Yet in the absence of acquired training, nurses would not feel competent enough to fulfill these obligations. A quasi experimental design was used to assess the importance of professional competency in determining self-efficacy and individual effectiveness among nurses (Gibson 2001). Findings suggest that self-efficacy and 
individual effectiveness were higher among nurses who received training in comparison to those who did not (Gibson 2001). In yet another instance, nurses in Uganda have not only expressed the importance of sustained training in management and acknowledged the importance of leadership beyond nursing, but have also been more reluctant to identify themselves as leaders based on inadequate education in the field (Ziegler, et al. 1997).

\section{$H_{4}$ : Competency positively affects decision making.}

\section{Structural determinants}

Information availability. Information exchange has been reported to be an important factor

allowing for decision making. For example, Barnet (1983) discusses, the profession of nursing in its current status, entitles nurses to a sense of "freedom to gain information." Information pertaining to techniques or methods of seeking solution, which are patient centric in nature, is very important for educated decision making (Barnet 1983).

The nursing home represents one of the more complex arenas where decision making is largely based upon effective communication. The limited nature of quick telephone based consultation between physicians and nurses, or the nurse having to step in without adequate information, leads to ineffective decision-making (Kayser Jones 1995). Rathwell and Burns (1985) argue that distributed decision-making is contingent on "transactions and conversations between groups with different interests and perspectives". The authors further argue that exchange of information is pivotal for cooperation since different groups might not share the same interest or priority (1985). Retrieval, generation, sharing and usage of information are central to distributed decision making in an organization (Rathwell \& Burns 1985). In addition, Kanter (1979) has suggested that effective information flow, needs to be in place in order for "Front Line Workers" such as NAs to be able make work related decisions. 


\section{$H_{5}$ : Information availability is positively related to the extent of individual decision}

making among NAs

Support of coworkers and supervisors. Support from the medical community (co-workers and supervisors) has been reported to be important for decision-making. It is reasonable to suspect that co worker and management support directly affects a NA's ability to make decisions.

Without support from peers and supervisors, CNAS making decision would be unable to carry out the decision making process.

The reinforcement of supervisors and peers has a positive effect on authority and decision making, when nurses are in charge. In the modern parlance of organizational management, Kanter (1979) argues that the nature of relationships in an organization is more horizontal than vertical, and managers need the "tacit approval" of other key figures in an organization--this can used as a resource for power and authority. In the context of the nursing profession, the Block Nurse Program in Minnesota brings care into the homes of chronically ill individuals (Martison, et al. 1985). A nurse attends to several homes within the same vicinity and is supported by physician, social workers and other members of the medical community. (Martison et al. 1985). With this support the nurse is able to make health related decisions regarding the individuals. This suggests the following:

\section{$H_{6}:$ Supervisor and coworker support positively affects nurse aide's decision making.}

Shared governance. Over the years shared governance (also referred to as participatory decisionmaking) has become an important addendum to the workplace environment (Hess 1995). It is logical to assume that nursing homes, which inculcate this collective authority structure, are more conducive for autonomous decision-making processes. Shared governance or collaborative decision-making can be regarded as an important prelude to individual decision making. Nursing 
homes that have encouraged NA participation in collaborative decision-making are likely to buttress their independent decision-making capabilities.

Cohen (2002) in his work the "Modern Times" compares two models of management that has increased worker productivity in the nineteenth century--the 'Fordian' which looks at wage enhancement as a means to increase work morale, versus the more recent 'Toyota' model which looks at a more 'bottom-up' labor participation technique in production process. In comparison to the Ford model, the Toyota model has enhanced worker participation in the more recent years and also accounts for the relative success of the Japanese industry (Cohen 2002).

Hess (1995) provides an interesting perspective on shared governance - the fact that it entails a totality of power, control, authority, and influence (Hess, 1995). In the domain of nursing, shared governance takes away from the rigid hierarchical structure of organization (which separates management from professional practice) and instead, bestows partial authority to the nurses. The important discretion for shared governance is controlled practice. (Hess 1995). Controlled nurse practices include a wide array of practices, one of which is decision-making (Kramer et al. 2008). The outcome from engaging in decision making is important in delivering quality care and in contributing toward a sense of fulfillment (Kramer \& Schmalenberg 2003).

For the purpose of the current analysis, participation in decision-making processes, (rather than individual decision-making which is subsequent to it) will be regarded as an indicator of shared governance.

$H_{7}$ : Shared decision-making positively affects decision-making. 
Figure One. Factors Affecting Structural Empowerment

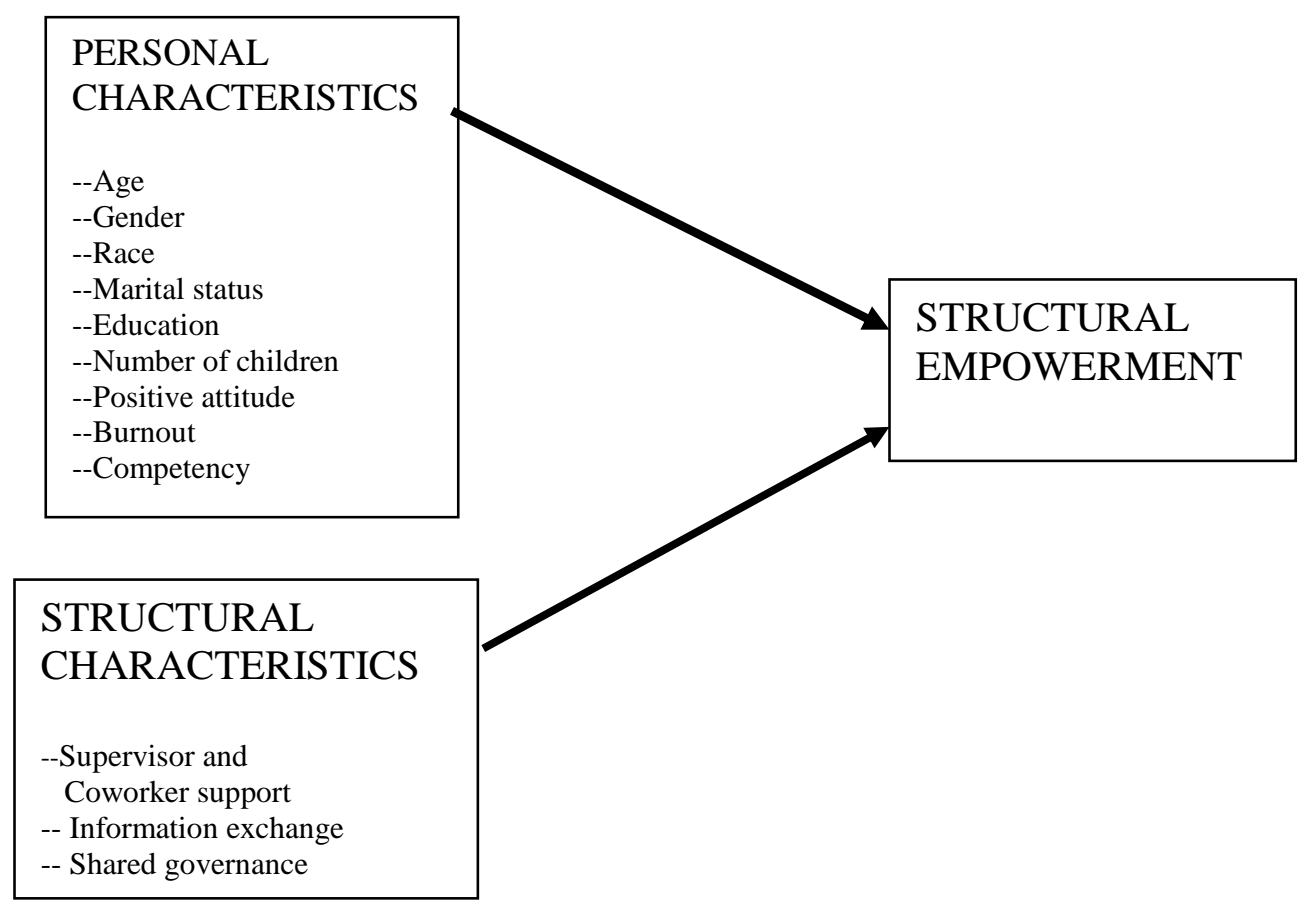

\section{METHODS}

Data collection procedure. The data for this study come from a larger research project designed to examine CNA empowerment. Using a self-administered survey instrument, directcare workers (DCWs) were surveyed at 11 nursing homes (NHs). The questionnaires were distributed to the DCWs during a staff meeting. For those DCWs who did not attend this staff meeting, a researcher later attempted to locate each DCW individually during her or his working hours and requested her or him to complete the instrument. In some cases, this included visits to the NH very late at night or very early in the morning. In a few cases where a DCW was difficult to reach, the instrument was left at the $\mathrm{NH}$ and then picked up at a later time by the researcher. The response rate was approximately 65 percent. DCWs include 367 nurse aides and 5 
uncertified nurse aides. Only certified and the 10 uncertified nurse aides $(\mathrm{N}=372)$ were included in the final analysis.

Independent and dependent variables. There are six predictor variables and one dependent variable in the study. The predictors include six background indicators as well as variables representing personal and structural characteristics. Personal characteristics include competency, positive attitude (upbeat mindset brought into the profession) and burnout (emotional exhaustion). The structural factors on the other hand include information exchange, support (coworker and supervisor support), and participation in decision-making (shared decision-making with management). Each index measure underlying the independent and dependent variables comprised of a series of statements. For example, to measure the dependent variable decision-making, five individual statements were used with responses ranging between 'strongly disagree' to 'strongly agree'. These Likert statements are taken from existing instruments if available including concepts on empowerment and work related variables developed by Cook and colleagues (1979), and were modified to reflect the unique environment of a nursing home. All he predictors (except demographic variables) and the dependent variable were measured as indices comprising of two or more Likert statements added together and then divided by the number of indicators (see Appendix One for specific statements used). For example, the index "information exchange" was created adding the responses for 2 different statements: "I am given regular updated info on any changes concerning residents" and "I am given all the information I need about new residents". The sum was then divided by 2 so that the mean values of the predictors would still range between 1 and 5 (between strongly disagree and strongly agree). Similarly dependent variable "decision-making" was created by summing five statements and dividing the sum by $5(\alpha=.64)$. Reliability tests and accompanying Cronbach's 
alpha scores were used to verify the appropriateness of combining the Likert statements. The majority of the CNA indices ranged between $\alpha=.60$ to $\alpha=.80$ (See Appendix One). Factor analysis (Varimax, Pattern and Structure) was run to identify questionnaire items reflecting the concepts of interest. The dimensions that emerged from the factor loadings largely correlated with the personal and structural predictors.

Descriptives (mean, standard deviations and percentages) for all the variables, bivariate (correlation) and multivariate (OLS regression) relationships among the predictor and dependent variable was examined using SPSS. For all four regression models, dummy variables representing nursing homes were included to hold constant the potential effects of the facilities on decision-making. Nursing home 7 with the highest number of respondents was used as a reference category.

The demographic characteristics include age, highest level of education (continuous measures), sex, number of children at home, marital status and race. Dummy variables were created for race with "Whites" as a reference category. Similarly, for gender, female was used as a reference group. Marital status was recoded into "In a relationship/Married" and "Single", with Single as reference category.

Among the demographic predictors, the mean age reported among the nurse aides is about 37 years (Appendix Two). On average, respondents reported having almost 12 years of formal education. The average number of children at home is 1.52 . The number of females in the sample (85.5\%) outnumbers men substantively $(12.4 \%)$. There were more Blacks represented in the sample $(43.3 \%)$ than Whites $(38.2 \%)$ or Others $(9.7 \%)$. Some of the "Others" were affiliated with Non White Hispanic/ Latino/Spanish lineage as well as individuals who were 
immigrants from other nations. In addition, majority of the respondents (49\%) reported being in a relationship/married.

An examination of the predictor variables revealed that most respondents score high on competency (4.22 on a scale of 5) as well as on the extent of self-reported positive attitude (almost 4.0 on a scale of 5). Scores for coworker and supervisor support are moderate (3.66 and 3.33 respectively), followed closely by information exchange (3.09). The average score for participation in shared decision-making is little less than moderate (2.59). The average score for burnout is also low (2.55).

The average score for decision-making among nurse aides (the main dependent variable) is also moderate (2.83)--that is when averaging the item responses from statements as "CNAs decide the order in which to do things" and "CNAs decide procedures for getting residents to the dining room", the average response was between 2.0 (disagree) and neutral (3.0).

\section{FINDINGS}

Table One shows four regression models. Model One includes only demographic/control variables, Model Two includes personal and demographic characteristics. Model Three incorporates structural, personal and demographic variables while Model Four removes the control variables (except race—which had a significant effect on decision-making).

Model One shows that being Black was negatively associated with decision-making. In comparison to Whites who are the reference category for race, Blacks were less prone to making decision in the work place (Bivariate relationship between Blacks and Others was also significant --See Appendix C). In Model One, none of the other variables including gender, age, education, number of children and marital status or the dummies for nursing homes had a significant effect on the extent of decision-making. Thus, Blacks was the only demographic 
variable that explained decision-making. The adjusted $\mathrm{R}$ square reported was .03 — only three percent of the variation in the dependent variable decision-making could be attributed to the changes in the demographic predictors.

Model Two accounted for the effects of demographic and personal predictors on decision-making. Two of the three personal characteristics were significant in Model Two: burnout and positive attitude. Burnout is positively and significantly associated with decisionmaking - the higher the extent of burnout, the higher the extent of decision-making (every level increase in self-reported burnout increased decision-making by almost .17 units). Of all the predictors reported in Model Two, the Beta was the highest for burnout (.20) demonstrating that burnout impacted decision-making the most. Likewise for positive attitude, the higher the scope of positive attitude brought into the profession, the higher the extent of decision-making, controlling for demographic and other personal attributes (However--among the personal characteristics, the only significant bivariate association was between burnout and decisionmaking-See Appendix C). In addition, even when personal characteristics were accounted for, Blacks, continued to exhibit a negative and significant relationship with decision-making. The adjusted R square in this model slightly increased from .03 in Model One to .07 in Model Two. This however was not a significant increase as illustrated by comparison of the computed F statistic for checking exclusion restrictions (Woolridge, 2000) to the observed F value (from the F Table for $\mathrm{p}=.05$ ) (See Appendix D). Thus, the additional personal characteristics in Model Two fail to contribute significantly to variations in the dependent variable.

Model Three accounted for the effects of demographic, personal and structural characteristics on decision-making among nurse aides. In Model Three, the previously observed effects for Blacks were no longer significant. The unique effect of one nursing home facility was 
also significant (not shown in table), indicating that this particular nursing home had an unusually number of high nurse aides who made decisions on their own. Further "Others" as race had a significant impact on decision-making. In this case, NA's who belong to "other" races are more likely to make their own decisions in comparison to "white" nurse aides.

Two of the four structural variables-supervisor support and participation in shared decision-making had a significant effect on decision-making, controlling for other variables in the model (Also observed in the bivariate relationships-see Appendix C). There was a positive and significant association between supervisor support and decision-making. The higher the extent of supervisor support, the higher the extent of decision-making. Similarly, participation in decision-making had a positive and significant effect on decision-making. The standardized betas show burnout had the largest impact on autonomous decision-makings (.28), closely followed by participation in decision-making (.26). The adjusted $\mathrm{R}$ square reported in Model Three was .15. The computed F statistic is higher than the observed F (See Appendix D). Therefore in comparison to Model Two, Model Three, with additional structural variables, significantly contributes towards explaining variations in the dependent variable decisionmaking.

In an attempt to reduce specification error, Model Four was calculated. It does not include the demographic variables that were not significant. Findings suggested the variables that were significant earlier, are still significant in Model Four: Both Blacks and Other races are significant in the fourth model. Among the personal factors, burnout still demonstrated a positive and significant effect on decision-making. Among the structural factors, supervisor support continued to have a positive and significant effect on decision-making. In the final model, information exchange had a marginally significant and negative relationship with decision- 
making ( $\mathrm{p}=.09$ ). In addition, in Model Four none of the nursing home dummies had a significant effect on decision-making, when the non-significant demographic predictors from earlier models were removed from analysis.

The adjusted R squared increased in this model to .169. The computed F statistics from comparing Model Four and Three (Model Three is still the unrestricted model with larger

number of variables) was 1.03, with a observed F of 4.36 (See Appendix D). The null hypothesis (In comparison to Model Four, Model Three provides a better explanation for variations across the dependent variable) could not be rejected. This validates that Model Three with a higher number of variables does not account for significant variations across the dependent variable in comparison to Model Four, since Model Four is better specified.

\section{DISCUSSION}

This research looked at the demographic, personal and structural determinants of decision-making among nurse aides as indicators of structural empowerment. The theoretical and practical implications of the findings are summarized in the subsequent section.

Theoretical implications. In contrast to gender, which was assumed to be an important predictor for factors affecting decision-making among nurse aides, race was taken into consideration only as a control. Yet in all the models, gender does not have an impact on decision-making (unlike the occupational trend in medical work reported by Kanter 1979, Horman, et al. 1987). The null for hypothesis one cannot be rejected. In comparison, in all three models, either Blacks (for Model One and Two) and “Other” Races (Model Three) transpired as significant factors. One explanation of lesser investment in decision-making by Blacks can be connected to lacking control over resources that enable decision-making. This alludes to the 
entire minority experience of being clustered in subordinate statuses and low end jobs with little possibility of actual advancement (Doeringer \& Piore, Dickens \& Lang 1975, Healey, 1975). In comparison, despite the slight presence of 'Other' races in the sample (besides Black and White), a substantive proportion of this sub demographic constituted of more recent immigrants from aboard, a higher percentage (60 percent) of whom identified with Spanish/Hispanic/Latino lineage. Getting immediate goals accomplished through decision-making, could be a potential means of upward mobility for this particular group. In comparison, individuals from the United States (both Blacks and Whites) are less likely to take such chances being accustomed to the methodical design of any organization.

Among the personal characteristics - burnout, which was significant in Model Two was also significant in Model Three and Four. Thus hypothesis Three was partially validated (the direction of burnout predicted was opposite). This unexpected direction of the findings can be attributed to the fact that when nurse aides get emotionally burnt out from the ritualistic modus operandi and waiting around for more instructions, under the circumstances they got more proactive and made autonomous choices on their own. Decision-making in this regard is an exodus from preexisting occupational fatigue that comes from optimally structured practices. Although Cordes and Dougherty's (1993) research discussed the negative effects of burnout on staff turnover, absenteeism, quality of care and lack of commitment, this research demonstrates an opposite effect of burnout on nursing home practice-- higher levels of burnout was likely to render itself into higher propensity to make decisions.

Among personal contributors, either positive attitude or acquired competency fails to have an overall impact when all three types of determinants (demographic, personal and structural) are factored in. In comparison to Model Two, positive attitude was not significant in 
Models Three and Four. The null for hypothesis two for positive attitude and hypothesis four for competency thus cannot be rejected. In contrast to Isen's (2001) articulation of positive attitude as ensuing self-reliance and other demonstrated evidence of competency enhancing health care delivery (Kanter 1989, Henke Jones 1988, Gibson 2001, and Ziegler et al. 1997), neither of the variables contributed to nurse aide empowerment through decision-making in this study.

In the structural realm, supervisor support and participation in decision-making shares a significant relationship with decision-making. Hypothesis six receives only partial validation since coworker support does not, and supervisor support alone-- effected decision-making. Thus, positive endorsement from superiors rather than peers, was likely to render itself into autonomous decision-making. The fact that "tacit approval" of other key figures in an organization is a resource for power and authority (Kanter, 1979) is reiterated by the fact that supervisor support was pivotal for nurse aide decision-making. Analogous to predicted hypothesis (seven), participation in decision-making had a positive and significant association with individual decision-making. Exposure to shared decision-making with management and supervisors obviously enhanced their levels of confidence in being able to initiate such objectives. Consistent with established trend of research (Hess, 1995; Kramer, et al., 2008; Kramer \& Schmalenberg, 2003) shared decision-making goes a long way in establishing individual autonomy.

In the final model, information exchange had a marginally significant and negative relationship with decision-making $(\mathrm{p}=.09)$. Counter intuitive to the direction of the predicted hypothesis (five) and trend observed in literature (Kayser Jones 1995, Rathwell \& Burns 1985 and Kanter 1979), greater availability of information suggested more protocols, more rules and directions to follow. Instead, individuals who intend on being more upbeat about their situations 
are likely to go ahead and make the decisions without explicit instructions and up to date information. In this regard, information exchange and burnout complement each other. However in Model One, Two and Three information exchange does not have a significant effect on decision-making. The null for hypothesis five thus cannot be rejected.

The overall theoretical implications include the importance of exploring race as one of the central determinants of structural empowerment among nurse aides, specifically because the profession is characterized by high minority participation. In addition, the nature and type of burnout that propel decision-making needs to be examined in depth because positive mindset or acquired competency, irrespective of being formal and informal credentials brought into the profession, does not contribute to decision-making. In the structural realm, ongoing scholarship that looks at both supervisor support and shared authority structure as separate and allied concepts conducive to nurse aide empowerment, warrants consideration.

Practical implications. There are three important practical implications for this research. Race plays an important role in structural empowerment: among "other races" minority affiliation enhances decision-making, while for Blacks, race could work as a deterrent. Similar to the instance of "other" races, decision-making capability also has to be encouraged among the minority demographic. This can be fostered by direct supervisor support as well as soliciting shared governance since the structural contributors in general has proven to be effective. Second, irrespective of the years of competency and training or very positive mind set brought into the profession, it is occupational fatigue that is driving nurse aides into self-reliance. A caution needs to be exercised here- too much of burnout propelled by the exhausting modus operandi of nurse aides can also have a detrimental impact. Rather than encouraging autonomous decisionmaking, they might be instigated to exit the organization or their current professional roles. Thus 
continuous positive endorsement from supervisors, as well as more inclusive work environment where the nurse aides are exposed to shared decision-making, could make possible personal growth. Administrators should also buttress the importance of horizontal team formations that enhances cooperation and positive feedback among the nurse aides. Put together, these structural initiatives would bolster nurse aide empowerment that in turn leads to better quality of care in a nursing home setting. 
AUTHOR CONTRIBUTIONS:

Study Design (Initials): D.Y.

Data Collection and Analysis (Initials) D.Y., T.C.

Manuscript Preparation (Initials) T.C, D. Y. 


\section{REFERENCES}

Wilson-Barnett J (1983). Ethical Dilemmas in Nursing. Journal of Medical Ethics, 12, 123-126.

D Cohen (2002) Our Modern Times: The Nature of Capitalism in Information. Age. MIT Press: Massachusetts.

Cohen, S and S D Pressman. Positive Affect and Health. Current Directions in Psychological Science 15 122-125.

Cordes, C L. and Dougherty T. W. (1993) A Review and an Integration of Research on Job Burnout. The Academy of Management Review, 18, 621-656.

Day, JA and Berman HJ (1989). Introduction. In Successful NA Management in Nursing Homes, (Day JA and Berman HJ ed). Oryx Press: Arizona. pp. xi-xix

Dickens WT and Lang K (1985). A Test f Dual Labor Market Theory. The American Economic Review 75, 792-805.

Doeringer PB and Piore MB (1971). Internal Labor Markets and Manpower Analysis. Lexington Lexington, United Kingdom.

Gibson, C. B. (2001). Me and Us: Differential Relationships among Goal-Setting Training, Efficacy and Effectiveness at the Individual and Team Level. Journal of Organizational Behavior 22, 789-808.

Healey JF (2009). Race, Ethnicity, Gender and Class: The Sociology of Group Conflict and Change. Pine Forge: Los Anegeles.

Hess, R. (1995). Shared governance: Nursing's 20th century Tower of Babel. Journal of Nursing Administration 25, 14-17.

Isen, A M. (2001). An Influence of Positive Affect on Decision-making in Complex Situations: Theoretical Issues with Practical Implications. Journal of Consumer Psychology 11, 75-85.

Jones, LH. (1988). AIDS, Education, and the Community Health Nurse. Journal of Community Health Nursing 5, 159-165.

Kanter, R (1979). The Impact of Hierarchical Structures on the Work Behavior of Women and Men. Social Problems 23, 415-430.

Kanter, R (1979). Power Failure in Management Circuits. Harvard Business Review 57, 65-75.

Kanter, R (1981) Leadership, and Participatory Management Theory into Practice 20, 219-224.

Kanter, R (1989). The New Managerial Work. Harvard Business Review 67, 85-93 
Kayser-Jones, J (1995). Decision-making in the Treatment of Acute Illness in Nursing Homes: Framing the Decision Problem, Treatment Plan, and Outcome. Medical Anthropology Quarterly 9, 236-256.

Kramer, M and Schmalenberg C.E. (2003). Magnet Hospital Nurses Describe Control Over Nursing Practice. Western Journal of Nursing Research 25, 434-452.

Kramer, M, Schmalenberg C, Maguire P, Brewer B B, Burke R, Chmielewski L, Cox K, Kishner J, Krugman M, Meeks-sjostrom D and Waldo M. (2008). Structures and Practices Enabling Staff Nurses to Control Their Practice. Western Journal of Nursing Research 30, 539-559.

Martinson, IM., Jamieson MK, O'Grady B and Sime M. (1985). The Block Nurse Program. Journal of Community Health Nursing 2, 21-29.

Maslach, C., \& Jackson, S. E. (1981). The Measurement of Experienced Burnout. Journal of Occupational Behavior, 2, 99-113.

Maslach, C., Jackson, S. E., \& Leiter, M. P. (1996). The Maslach Burnout Inventory. Palo Consulting Psychologists Press: Alto, CA

Mills, PK and Ungson GR (2003) Reassessing the Limits of Structural Empowerment: Organizational Constitution and Trust as Control. The Academy of Management Review 28, 143-153.

Rathewell, M and Burns A (1985). Information Systems Support for Group Planning and Decision-Making Activities. MIS Quarterly, 9, 255.

Seibert, S E., Silver SR and Randolph WA (2004). Taking Empowerment to the Next Level: A Multiple-Level Model of Empowerment, Performance, and Satisfaction. The Academy of Management Journal 47, 332-349.

Spreitzer, G.(1995). Psychological Empowerment in the Workplace: Dimensions, Measurement, and Validation. The Academy of Management Journal, 38, 5, pp. 1442-1465.

Thomas, K. W., \& Velthouse, B. A. 1990. Cognitive Elements of Empowerment. Academy of Management Review, 15: 666-681.

Toppinen-Tanner S, Kalimo R, Salla PM (2002) The Process of Burnout in White-Collar and Blue-Collar Jobs: Eight-Year Prospective Study of Exhaustion. Journal of Organizational Behavior, 23, 555-570.

Woolridge, J 222. Introductory Economics: A Modern Approach. Southern Western Colelge Publsihing: United States

Yeatts, DE., Cready C, Ray B, DeWitt A and Queen (2004). Self-Managed Work Teams in Nursing Homes: Implementing and Empowering NA Teams. Gerontologist 44(2):256-261. 
Ziegler, Priscilla B., Henerika Anyango and Henry D. Ziegler. (1997). The Need for Leadership and Management Training for Community Nurses: Results of a Ugandan District Health Nurse Survey. Journal of Community Health Nursing 14, 119-130. 
Table One. OLS regression estimates predicting determinants of structural empowerment, i.e. decision making among Nurse Aids.

\begin{tabular}{|c|c|c|c|c|c|c|c|c|}
\hline \multirow[b]{2}{*}{ Variables } & \multicolumn{2}{|c|}{ Model One } & \multicolumn{2}{|c|}{ Model Two } & & \multicolumn{2}{|c|}{ Model Three } & Model Four \\
\hline & B & Beta & $\mathrm{I}$ & Beta & & $\mathrm{B}$ & Beta & Beta \\
\hline Sex (1=Male) & -.037 & -.018 & .013 & .006 & -.070 & -.033 & --- & --- \\
\hline Age in years & .002 & .028 & .002 & .029 & .000 & .005 & --- & --- \\
\hline Education & .019 & .022 & .016 & .046 & .010 & .029 & --- & --- \\
\hline $\begin{array}{l}\text { Marital (1= in a } \\
\text { Relationship) }\end{array}$ & -.126 & -.088 & -.135 & -.093 & -.160 & -.110 & --- & --- \\
\hline Number of children & -.050 & -.103 & -.043 & -.087 & -.028 & -.056 & --- & --- \\
\hline $\begin{array}{l}\text { Black (Whites= } \\
\text { Reference category) }\end{array}$ & -.306 & $-.212 * *$ & -.275 & $-.188 * *$ & -.161 & -.110 & -.211 & $-.147 *$ \\
\hline Other & .274 & .112 & .240 & .098 & .325 & $.131 *$ & .370 & $.155^{* * *}$ \\
\hline Competency & --- & --- & -.038 & -.033 & -.015 & -.013 & -.024 & -.024 \\
\hline Burnout & --- & --- & .166 & $.200 * *$ & .237 & $.286 * * *$ & .188 & $.223 * * *$ \\
\hline Positive attitude & --- & --- & .158 & $.134 *$ & .095 & .081 & .100 & .084 \\
\hline Supervisor support & --- & --- & --- & --- & .114 & $.147 *$ & .098 & $.123^{*}$ \\
\hline Coworker support & --- & --- & --- & --- & .018 & .019 & .018 & .019 \\
\hline Information exchange & --- & --- & --- & --- & -.055 & -.081 & -.075 & -.114 \\
\hline Participatory decision making & --- & --- & --- & --- & .273 & $.261 * *$ & .286 & $.284 * * *$ \\
\hline $\mathrm{N}$ & & 253 & & 246 & & 243 & & 332 \\
\hline (Constant) & & 2.811 & & 1.976 & & 1.137 & & 1.143 \\
\hline Adjusted R Squared & & .037 & & .070 & & .15 & & .169 \\
\hline $\mathrm{R}$ square & & .102 & & .146 & & .234 & & .217 \\
\hline
\end{tabular}

${ }^{*} \mathrm{p}=? .05 \quad{ }^{* *} \mathrm{p} \leq .005 \quad{ }^{* * *} \mathrm{p} \leq .001$ (One tailed test) 


\title{
Appendix One. Items used to create Indices and corresponding Cronbach's Alpha
}

Variables $\quad$ Alpha

\section{Dependent Variable}

Decision-making

\author{
1. CNAs decide who will do what each day \\ nursing home \\ 2. I am allowed to make my own decisions about how \\ I do my work \\ 3. CNAs decide the order in which to do things \\ 4. While at work I make many decisions on my own or with \\ other CNAs \\ 5. CNAs decide procedures for getting residents to the dining room
}

Independent variables

I. Background characteristics

1. Race

2. Marital status

3. Age

4. Education level

5. Sex

6. Number of children at home

II. Information exchange

1. I am given regular updated info on any changes concerning residents

2. I am given all the info I need about new residents

III. Support from medical community

A) Coworker support

1. I had the support that I need form other CNAs to do a good job

2. I can trust the other CNAs I work with to lend me a hand if

I need to

3. I had the support I need from other nurse aides to do a good job

B) Supervisor support

1. The charge nurse listens to the suggestions of CNAs

2. When CNAs make decisions on how to do the work, charge nurses, consider their suggestions seriously

3. I can trust the charge nurses I work with, to lend me a hand if I need it

IV. Positive attitude/affect

1.I can easily understand how my residents feel about things

2. I deal very effectively with problems of my residents

3. I can create a relaxed atmosphere for my residents

V. Competency

1. I had all the skills and knowledge to do a good job and I use them

2. I had all the skills and knowledge to do a good job and I use them 
1. I feel burned out from my work

2. I feel emotionally drained from my work

3. I feel used up at the end of my shift

4. Working with people all day is a strain on me

VII. Participation in decision-making

1. I work with the management staff in making decisions about my work

1. The management staff ask the CNAs for their opinion before making decision about CNA's work

2. CNAs are asked to help make decisions about their work

3. CNAs work with management staff in making decision about CNA work

4. Whenever CNA work must be changed, the CNAs are usually asked how they think the work should be changed 
Appendix Two. Descriptive: Predictor and Dependent variables

\begin{tabular}{|c|c|c|c|c|}
\hline Variables & Mean & SD & $\%$ & No. of cases \\
\hline Age in years & 36.68 & 11.825 & & 332 \\
\hline Sex & 1.13 & .333 & & \\
\hline Male & & & 12.4 & 46 \\
\hline Female & & & 85.5 & 318 \\
\hline Education & 11.81 & 2.012 & & 322 \\
\hline \multicolumn{5}{|l|}{ Race } \\
\hline White & .41 & .49 & 42 & 142 \\
\hline Black & .47 & .50 & 47.5 & 161 \\
\hline Other & .10 & .30 & 10.6 & 36 \\
\hline Maritalstatus & .52 & .500 & & \\
\hline In a relationship/married & & & 48.9 & 182 \\
\hline Single & & & 45.7 & 170 \\
\hline Number of children living at home & 1.52 & 1.569 & & 342 \\
\hline Competency & 4.22 & .685 & & 354 \\
\hline Burnout & 2.55 & .855 & & 341 \\
\hline Positive attitude & 3.92 & .620 & & 358 \\
\hline Supervisor support & 3.33 & .93 & & 352 \\
\hline Coworker support & 3.66 & .777 & & 349 \\
\hline Information exchange & 3.09 & 1.081 & & 355 \\
\hline Participation decision-making & 2.59 & .721 & & 341 \\
\hline Decision-making & 2.83 & .781 & & 334 \\
\hline
\end{tabular}


Appendix Three: Correlation between predictors and dependent variables

\begin{tabular}{|c|c|c|c|c|c|c|c|c|c|c|c|c|c|c|c|}
\hline Variables & 1 & 2 & 3 & 4 & 5 & 6 & 7 & 8 & 9 & 10 & 11 & 12 & 13 & 15 & \\
\hline $1 \mathrm{DM}$ & 1 & & & & & & & & & & & & & & \\
\hline 2 Age in years & 0.008 & 1 & & & & & & & & & & & & & \\
\hline $3 \mathrm{Sex}$ & 0.046 & $-.189 * *$ & 1 & & & & & & & & & & & & \\
\hline 4 Highest year of & -0.030 & -0.018 & 0.026 & 1 & & & & & & & & & & & \\
\hline 5 Black & $-.214 * *$ & 0.040 & -0.001 & $.193 * *$ & 1 & & & & & & & & & & \\
\hline 6 Other race & $.187^{* *}$ & -0.014 & 0.069 & -0.088 & $-.317 * *$ & 1 & & & & & & & & & \\
\hline 7 Number of children & -0.093 & 0.004 & -0.098 & 0.024 & $.134 *$ & 0.072 & 1 & & & & & & & & \\
\hline 8 married or relationship & -0.101 & -0.102 & 0.000 & -0.022 & -0.066 & 0.074 & $.230 * *$ & 1 & & & & & & & \\
\hline 9 Competence & -0.004 & 0.079 & -0.035 & 0.053 & $.116^{*}$ & -0.071 & 0.058 & 0.091 & 1 & & & & & & \\
\hline 10 Burnout & $.135 * *$ & $-.122 *$ & -0.004 & 0.076 & -0.090 & 0.048 & -0.030 & -0.023 & $-.139 * *$ & 1 & & & & & \\
\hline 11 Positive attitude & 0.074 & $.118 *$ & -0.049 & 0.001 & 0.075 & -0.037 & 0.003 & 0.049 & $.438 * *$ & $-.226^{* *}$ & 1 & & & & \\
\hline 12 Supervisory support & $.153 * *$ & $.171 * *$ & 0.008 & -0.010 & 0.025 & -0.066 & -0.027 & -0.018 & $.112 *$ & $-.274 * *$ & $.202 * *$ & 1 & & & \\
\hline 13 Coworker support & 0.083 & 0.031 & 0.072 & $-.159 * *$ & 0.006 & 0.037 & 0.077 & 0.077 & $.195 * *$ & $-.228 * *$ & $.206^{* *}$ & $.341 * *$ & 1 & & \\
\hline 14 Information exchange & -0.031 & $.119 *$ & -0.011 & 0.034 & $.237 * *$ & -0.004 & 0.077 & 0.038 & $.157 * *$ & $-.318 * *$ & $.130 * *$ & $.453 * *$ & $.331 * *$ & 1 & \\
\hline $\begin{array}{l}15 \text { Pparticipation } \\
\text { in decision making }\end{array}$ & $.254 * *$ & 0.050 & 0.095 & 0.002 & 0.030 & 0.004 & -0.007 & 0.013 & 0.021 & $-.271 * *$ & $.146^{* *}$ & $.458 * *$ & $.296 * *$ & $.477 * *$ & 1 \\
\hline
\end{tabular}


Appendix Four. R square form of F statistics for checking exclusion restrictions between OLS regression models

(i) F test for comparing Models One and Two:

$\mathrm{F}$ statistic $=\quad \mathrm{R}$ square unrestricted-R square restricted $/ \mathrm{q}$

(1-R square restricted) / (N-K-1)

$\mathrm{q}=$ number of categories dropped form the unrestricted to the restricted models (numerator degrees of freedom),

$\mathrm{K}=$ number of independent variables in unrestricted models,

$\mathrm{N} \quad=$ sample size of unrestricted model,

$\mathrm{N}-\mathrm{k}-1$ = denominator degrees of freedom.

$.146-.102 / 3$

$\overline{1-.146 /(246}-10-1)$

$$
=.044 / 3=.014=3.8\left(\mathrm{~F}_{1}\right)
$$$$
\overline{.854 / 235} \overline{.0036} \text {, }
$$

Where $\mathrm{q}=3=$ the three personal attributes missing in Model One, $\mathrm{K}=10=$ total number of variables in the unrestricted Model Two And $\mathrm{N}=246$ observations from the unrestricted Model Two.

Comparing the computed F statistic (3.8) with the value from the F table for $\mathrm{q}=3$ numerator degrees of freedom, and $235=$ denominator degrees of freedom, the F observed is 8.53 at $\mathrm{p}=.05$. The computed $\mathrm{F}$ value is not within the critical region of rejection of the null hypothesis $\left(\mathrm{N}_{0}=\right.$ Personal attributes does not contribute significantly to exploratory power of Model Two).

(ii) F test for comparing Models Two and Three:

$$
\begin{array}{lrr}
.234-.146 / 4 & =.088 / 4 & =.022 \\
\overline{1-.234 /(243-14-1)} & \overline{.766 / 228} & . \overline{0033}
\end{array}
$$

Comparing the obtained F statistic (6.6) with the observed $F$ from the $F$ table for $q=4$ numerator degrees of freedom, and $228=$ denominator degrees of freedom, F observed is 5.63 $(\mathrm{p}=.05)$. The computed $\mathrm{F}$ statistic is higher than the observed $\mathrm{F}$ and therefore the null 
hypothesis $\left(\mathrm{N}_{0}=\right.$ structural characteristics does not contribute significantly to exploratory power of Model Two) was rejected.

(iii) F test for Comparing Model Four and Three ( Model Three = unrestricted Model):

$$
\begin{array}{cl}
.234-.217 / 5 & =.017 / 5=.0034=1.03\left(\mathrm{~F}_{3}\right) \\
\overline{1-.234 /(243}-14-1) & \overline{.766 / 228} \quad \overline{.0033}
\end{array}
$$

Comparing the computed $\mathrm{F}$ statistic (1.03) with the observed $\mathrm{F}$ from the $\mathrm{F}$ table for $\mathrm{q}=5$ numerator degrees of freedom, and $228=$ denominator degrees of freedom, F observed is 4.36 at $(\mathrm{p}=.05)$. The null hypothesis that Model Three provides a better explanation for variations across the dependent variable, in comparison to the limited Model Four could not be rejected. 